\title{
Methodological Approach for Evaluation and Improvement of Quality Transport Service in Public Road Passenger Transport
}

\author{
Tomislav BUBALO*, Marijan RAJSMAN, Pero ŠKORPUT
}

\begin{abstract}
Achieving the appropriate level of quality transport service is essential in the operations of the carriers in the public road intercity line passenger transport due to an increased competition between road carriers in the market of transport services. Effective assessment of achieved competitiveness is important for the survival and development of public road passenger carriers. The problem of research is reflected in the appropriate organization and giving importance to the criteria of quality of transport service in order to improve the methodology of its evaluation with the aim of optimizing business and competitiveness in public road intercity line passenger traffic. An efficient method for evaluating the quality of transport service would solve the problem of assessing the quality of transport service and assessing the competitiveness of bus carriers. It is proposed to develop a multi-criteria model for evaluating the quality of transport services by the method of measuring passenger satisfaction. The developed VAZP model (Multicriteria Analysis of Passenger Satisfaction) is based on multicriteria analysis AHP (Analytical Hierarchical Process) which is based on the disaggregated approach and linear programming modeling. The results of the research will be described using numerical values and will be graphically presented using descriptive statistical analysis. The ability to qualitatively represent passenger's judgments and preferences makes the model a suitable tool for assessing passenger satisfaction and evaluating quality service in the transportation sector, as well as strategically positioning and gaining a competitive opportunities in the transportation services market. Using the Expert Choice software tool and sensitivity analysis it would establish differences between reached level of the quality of transport service of individual bus carriers and propose possible improvements to the business to gain a competitive advantage in the market of transportation services. Systematic optimization and quality management through continuous assessment of market competitiveness contributes to the development of the business of companies for road passenger transportation.
\end{abstract}

Keywords: customer satisfaction; linear programming; multi-criteria analysis (VAZP model); quality of transport service

\section{INTRODUCTION}

Nowadays, the success of business and development of any organization, the level of satisfaction of users, carriers, and lasting and strong relationships with various business partners depend on the achieved level of quality. The quality management system implies the organizational structure, responsibilities, procedures and processes for achieving the goals of business management in road passenger transport companies. The quality management system places additional demands on the user and the carrier at the same time. It requires the user to clearly articulate his perception of quality, while he requires the carrier to have a unified procedure for proving the agreed level of quality of the transport service.

Given the market economy and the inevitable demand for profitability, an essential element of a successful transport business is the relationship of transport services offered by the transport company to the transport market in accordance with the state and trends of passenger transport demand and the optimization of the business system of carriers, primarily from the point of view of productivity and economy of business [1]. It can therefore be said that effective competitiveness evaluation is an important way to promote the efficiency of the operation and quality of passenger transport systems. In this respect, successful management of transport processes is reflected in constant business decision-making related to the development of the transport process and the efficient and effective carrying out of transport [2].

The structure of road transport technology in road traffic is determined by the structure of the environment and the structure of the traffic system in a certain space and a certain time. The structure of road transport technology in road traffic may also be other elements: natural, economic, security, management, and others [3]. With regard to the optimization of passenger transport in road transport, the basic objective is to achieve such a level of transport service quality that is appropriate to the needs of the modern citizen, especially in terms of attractiveness and for those who own the car and still give priority to individual transport. Line intercity passenger transport can be defined as a subsystem in the system of passenger transport in road traffic, which compensates for passenger demand on pre-established lines, fixed tolls, and carriers' tariffs under equal and pre-prescribed legal requirements for all types of transport service users [4].

By joining the European Union, domestic carriers got strong competition on the European transport market, requiring numerous qualitative adaptations and improvements not only for business improvement but also for survival on the market $[5,6]$. Therefore, a constant evaluation of competitiveness and improvement of road transport services is essential. According to the data available from the Croatian Chamber of Commerce and the Croatian Chamber of Trades and Crafts, 2395 road transport companies are registered in the Republic of Croatia, of which about $10 \%$ or 240 companies are registered for bus transportation of domestic and international road transport.

The system of public road passenger transport and the level of service quality (level of customer satisfaction) was a special subject of the EU Commission study at the Mobility Conference held in Paris in 2014. The research was conducted in cooperation with the International Association of Public Transport (UITP). The results of these studies show that EU residents are mostly satisfied with the public road transport service, as an exchange rate subsystem in the public transport system of passengers. The sample on which service satisfaction survey was conducted had 28,036 respondents. Different aspects of functioning and elements were studied in the public transport system of passengers. The following was concluded: in 23 out of 28 Member States, at least $60 \%$ of respondents indicate "high" or "good" level of satisfaction with the quality of transport services. At the top of the 
satisfaction list, there are residents of Luxembourg (88\% of respondents), Latvia (83\%) and Finland (82\%). At the bottom of the customer satisfaction level is Malta (31\%). According to the quality of transport services, the level of satisfaction of provided services is as follows: frequency $(69 \%)$, passenger information $(58 \%)$, accuracy $(58-70 \%)$, cleanliness of the passenger area $(58-70 \%)$, security $(58-$ $70 \%)$, reliability $(60-70 \%)$, route adaptability $(58-70 \%)$, and service cost (39\%) [7].

\section{LITERATURE REVIEW}

In the literature available, intercity line transport of passengers and the quality of the transport services are primarily investigated. It should be emphasized that there are few studies describing the quality management system in passenger transport at the level of transport companies. A review of research related to the assessment of the quality of transport services shows that public road passenger transport in developing countries faces a number of challenges. Some of the important ones are related to security and reliability issues [8]. Based on the above, there is a need to evaluate the quality of transport services in order to optimize operations and improve the competitiveness of road passenger transport companies. One possible solution is to use the multi-criteria VAZP model to assess the quality of transport services based on passenger satisfaction and their subjective assessments in public road passenger transport.

Passenger satisfaction, which is manifested through the quality of transport services, is the starting point and an effective tool for strategic positioning in the transport services market [9]. That passenger ratings help to assess the performance of public transport in intercity regular passenger traffic is shown by research $[10,11]$ where the authors analyze the expectations and perceptions of users in assessing the quality of public transport services. It was found that there is a difference between the expectations of users and the perception of carriers on the quality of transport service in bus transport. The results of the research confirm a difference in perception between regular and occasional transport users. Reliability and travel time have been found to be the most important elements of transport service quality.

The research [12] is a paper in which the authors analyze the satisfaction of users with public transport in Munich, suggesting that carriers regularly assess passenger's expectations in order to obtain information on possible improvements in service quality and thus their own competitiveness. The study [13] presents the results of a survey conducted in the Republic of Germany during the liberalization of the market in long-distance road passenger transport in 2013. It is shown how existing and potential users of bus transport evaluate the quality of service in relation to the choice of other alternative modes of transport (passenger car, rail transport, air transport). In research $[14,15]$, the authors categorized the elements of transport service quality into primary and secondary quality elements based on user preferences. They argue that a low level of quality of the elements (including accuracy, frequency and accessibility) can reduce the overall level of quality of the transport service. However, they believe that the absence of quality sub-criteria (including vehicle cleanliness and driver friendliness) must not jeopardize the quality of transport service as they are less important. Given that the authors in the research in a particular context state less importance of these subcriteria, in other categories of lines and research could seriously jeopardize the quality of transport service and distort the competitive advantage of the road carrier over other carriers in the market.

The differences in the quality of transport service and preferences based on a certain category of users are presented by the authors in the research [16, 17]. The authors in these studies found that there is a clear difference between a certain category of users (visitors / tourists) who prefer knowledge and kindness of drivers as key elements of service quality, while (University students) prefer ticket price as the most important quality element for bus carrier rating. Together, these studies show that regular users of public intercity road traffic tend to prioritize service reliability more than occasional users, while very few users are more influenced by information and service availability. Evaluation of transport service quality based on a hybrid model is presented in the research [18] where all information obtained by user perception is combined into a single information system from which the research resulted in an application solution for the management of a bus company.

In the paper [19], authors propose a new approach to improving the quality of transport services by applying AHP in obtaining weight criteria and new methods in ranking TOPSIS (Order Priority by Ideal Solution) where the conclusion was that courtesy, safety, and comfort were the highest ranked elements. The Quality of Service concept goes beyond the technical aspects of service delivery, encompassing the perception of passengers on what services should be and how services should be improved. The survey [20] assesses both criteria for determining the most important elements of the quality of transport service based on the measurement of passenger satisfaction and their subjective assessments regarding the offered quality elements. A further exploration is an overview of new methods for improving the quality and efficiency of bus operators by applying an integrated approach GAHP analysis (Group Analytic Hierarchy Process) and multi-criteria analysis of the set of alternatives used for ranking PROMETHEE (Ranking Organization Methods for Evaluation).

In addition, the paper [21] presents new strategies to improve the quality of transport services and competitive public transport based on group research and surveys where they describe the application of fuzzy multi-criteria analysis in the assessment of the quality of transport services. The approach presented is computer-efficient, and fuzzy estimates expressed in language terms are often the most influential way for the decision maker to use in the evaluation process. In order to ensure an efficient service and maintain the success of a passenger transport business, the bodies responsible for organizing and managing companies regularly assess the success of bus companies according to certain criteria. Depending on the objectives of the evaluation problem, various criteria for assessing public transport can be used from the perspective of different stakeholders. For example, a bus company would focus more on operational performance criteria 
while passengers are more interested in criteria such as quality of service and transportation security.

The assessor may also have other criteria of his own interest, such as social sensitivity. In the paper [22], authors present a new approach to assessing the quality of transport services based on the SEM (Structural Equation Model), model used to detect latent aspects describing the service, and provide a theoretical description of the relationship between the aspects and the quality of the service. It is also an interesting study [23] which provides an overview of the improvement of the quality of transport services in public road transport through the implementation of the SQI (Quality Index), model where comparisons of the efficiency of a bus carrier are based on known criteria and the level of quality of transport services. In the following research [24] a new model for assessing the quality of transport services is presented using a GOC model (Generalized Ordered Choice) which takes into account preferential heterogeneity through immediate parameters in the expected variant of service quality choice. In the research [25], the authors present a new approach to assessing the quality of transport services based on the model of artificial neural networks ANN (Artificial Neural Networks), where statistical analysis identified groups of quality elements with significant differences in their importance to determine their impact on quality of service provided.

Recent research related to the evaluation and improvement of transport service quality highlights a study [26] that represents the standardization of the overall level of transport service quality, which aims to minimize the differences between expected and provided transport service quality to stabilize passenger demand. Using general and specific scientific methods of cognition, the authors in [27] investigate the elements of transport service quality and their factors and explain their impact on the overall transport process in order to achieve a higher level of overall transport service quality. Recent research such as the study [28] deals with the analysis of the interaction between the evaluation of the transport service and the offered level of quality by the carrier after the use of the transport service.

\section{METHODOLOGY}

The proposed research is a contribution to the development of a methodology for evaluating the quality of transport services that is expected to contribute to the assessment and improvement of the competitiveness of bus carriers in public road intercity line passenger transport. The transport service strives to be organized in a way that is equally accessible to all, at an affordable price and with the aim of meeting customer expectations with special emphasis on limiting negative impacts such as environmental pollution, noise generation and traffic accidents. A new model for evaluating the quality of transport service by the method of measuring passenger satisfaction will be developed, which will combine multicriteria analysis based on a disaggregated approach and linear programming.

Measuring passenger satisfaction is one of the most important issues related to the business decisions of transport companies, which is justified by the philosophy of customer orientation and the main principles of continuous improvement of a modern company. In fact, measuring passenger satisfaction is one of the five major functions of management science that allows for understanding, analysis, and improvement. Measuring passenger satisfaction is now considered the most effective feedback, given that it provides effective, direct, meaningful and objective customer wishes and expectations. In this way, passenger satisfaction is a fundamental standard of performance and a possible standard of excellence for any transport company. The quality of transport service and the passenger satisfaction are an important basic determinant and dialogic framework of business in road passenger transportation companies.

The passenger's satisfaction measurement methodology is a linear regression approach used to estimate the passenger satisfaction function in such a way that the overall passenger satisfaction becomes as consistent as possible with the marginal judgments of the passengers. Every passenger in the survey is asked to express their judgments, their satisfaction according to a number of offered criteria of quality of transport service. Some of the criteria are divided into specific sub-criteria to formulate a more objective data output. The VAZP model provides quantitative measures of passenger satisfaction, by merging individual passenger judgments into a function of collective value. The main goal of the VAZP model is to combine individual judgments into a function of collective value under the assumption that overall passenger satisfaction depends on a set of criteria or variables that represent the dimensions of transport service quality elements (Fig. 1).

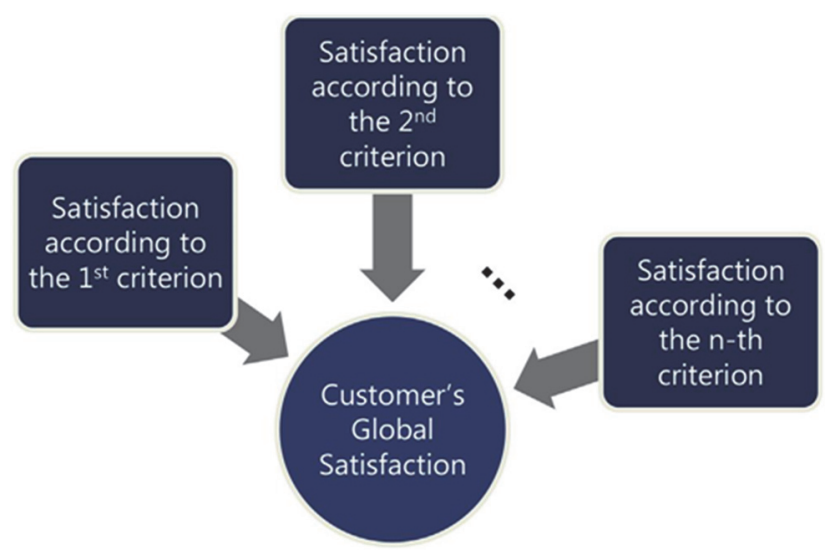

Figure 1 Aggregation of customer's preferences in VAZP method

The proposed model assumes that passenger satisfaction with the service depends on the set of $n$ criteria $X=\left(X_{1}, X_{2}, \ldots ., X_{n}\right)$, where $X_{i}$ is a variable representing the satisfaction dimension for (criterion) $i$. Through simple questionnaires the considered transport service is evaluated expressing the passenger's overall satisfaction $Y$ as well as his partial satisfaction $X_{i}$ for each criterio $i$. Passenger satisfaction can be shown on a predetermined regular scale with offered answers: very poorly satisfied, poorly satisfied, neutral, well satisfied, very well satisfied. Based on the collected data, the proposed model estimates the functions of partial pleasures $X_{i}^{*}$ and the global valueadded function $Y^{*}$, with respect to the estimates of passengers $Y$ and $X_{i}$. 
The model follows the principles of regression analysis under constraints using linear programming techniques. The regression analysis equation has the following form [29]:

$$
Y^{*}=\sum_{i=1}^{n} b_{i} X_{i}^{*} ; \sum_{i=1}^{n} b_{i}=1
$$

where $b_{i}$ is the weight value of criterion $i$, and $Y^{*}$ and $X_{i}^{*}$ are functions of values that are normalized in the interval $[0,100]$ to easily and directly understand passenger satisfaction. The following variables are also used:

Table 1 List of variables and their description

\begin{tabular}{|c|l|}
\hline Variable & \multicolumn{1}{|c|}{ Description } \\
\hline$Y$ & Customer's overall satisfaction \\
\hline$a$ & Number of global satisfaction levels \\
\hline$y^{m}$ & The $m$-th global satisfaction level $(m 1,2, \ldots, a)$ \\
\hline$n$ & Number of criteria \\
\hline$X_{i}$ & Customer's satisfaction according to the $i$-th criterion \\
\hline$a_{i}$ & Number of satisfaction levels for the $i$-th criterion \\
\hline$x_{i}^{k}$ & $\begin{array}{l}\text { The } k \text {-th satisfaction level of the } i \text {-th criterion }(k 1, \\
\left.2, \ldots, a_{i}\right)\end{array}$ \\
\hline$Y^{*}$ & Value function of $Y$ \\
\hline$y^{* m}$ & Value of the $y^{m}$ satisfaction level \\
\hline$X_{i}^{*}$ & Value function of $X_{i}$ \\
\hline
\end{tabular}

Normalization constraints for the value functions $Y^{*}$ and $X_{i}^{*}$ can be written as follows:

$$
\begin{aligned}
& y^{*}=0, y^{* a}=100 \\
& x^{*}=0, x_{i}^{* a i}=100 ; i=1,2, \ldots, n
\end{aligned}
$$

The goal of this model is to achieve maximum consistency between $Y^{*}$ and $Y$ using two error expressions in the linear regression equation:

$Y^{*}=\sum_{i=1}^{n} b_{i} X_{i}^{*}-\sigma^{+}+\sigma^{-} ; \sum_{i=1}^{n} b_{i}=1$

where $\sigma^{+}+\sigma^{-}$are the error of overestimation and underestimation. This equation is valid for a passenger who has expressed total satisfaction. For this reason, a pair of error variables should be estimated for each passenger separately (Fig. 2).

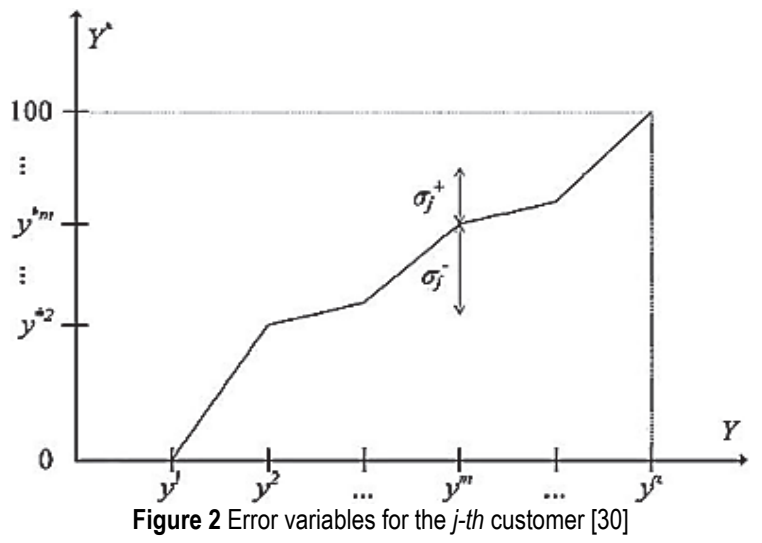

To reduce the size of the problem, transformation variables $z$ and $w$, are introduced which represent the successive steps of the functions $Y^{*}$ and $X_{i}^{*}$ respectively (Fig. 3):

$\left\{\begin{array}{l}z_{m}=Y^{* m+1}-Y^{* m} \text { for } m=1,2, \ldots, \alpha-1 \\ w_{i k}=b_{i} X_{i}^{* k+1}-b_{i} X_{i}^{* k} \text { for } k=1,2, \ldots, \alpha_{i}-1 \\ \text { and } i=1,2, \ldots, n\end{array}\right.$

Such transformation variables serve to formulate the initial non-linear problem (Eq. (3)). In this procedure, both variables $b_{i} X_{i}^{*}$ are estimated and formulated as a linear problem. The initial variables can be written by the following procedure:

$$
\left\{\begin{array}{l}
Y^{* m}=\sum_{t=1}^{m-1} z_{t} \text { for } m=2,3, \ldots, \alpha \\
b_{i} X_{i}^{* k}=\sum_{t=1}^{k-1} w_{i t} \text { for } k=2,3, \ldots, \alpha_{i} \text { and } i=1,2, \ldots, n
\end{array}\right.
$$

Using Eq. (5) and assuming that customer $j$ has expressed his/her global satisfaction $y^{t j}$ and his/her partial satisfaction $x^{t i j}$ using the ordinal scales $Y$ and $X_{i}$, the ordinal regression Eq. (3) can be written as:

$\sum_{m=1}^{t j-1} z_{m}=\sum_{k=1}^{t i j-1} w_{i k}-\sigma^{+}+\sigma^{-}, \forall_{j}$

Then final linear program can be written as:

$[\min ] F=\sum_{j=1}^{M}\left(\sigma_{J}^{+}+\sigma_{J}^{-}\right)$
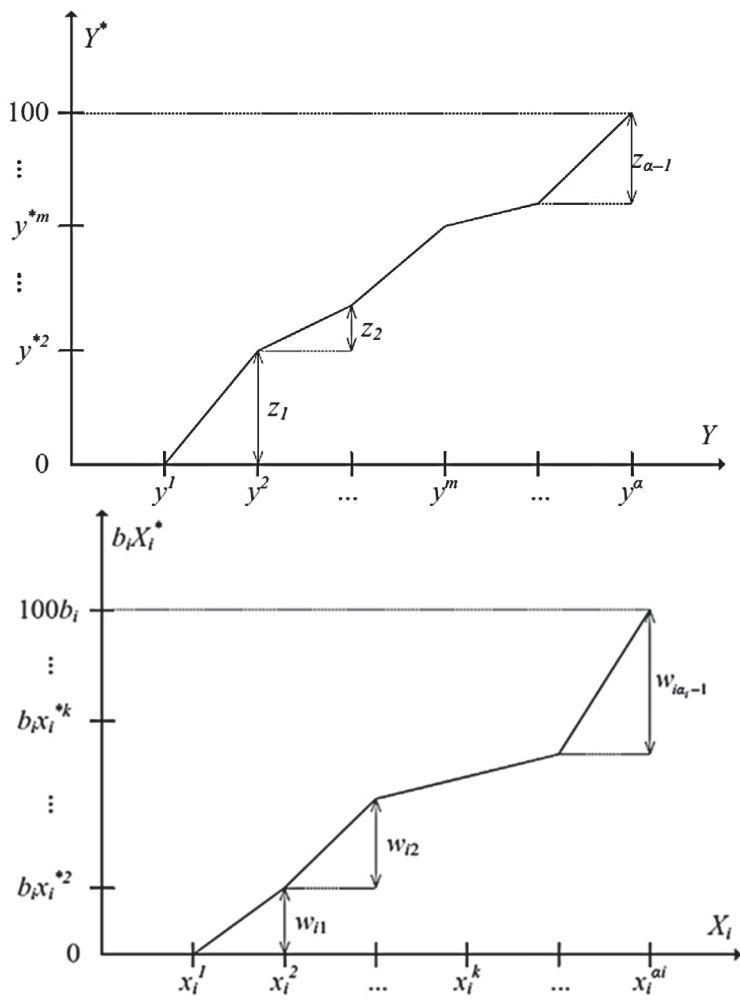

Figure 3 Transformation variables $z_{m}$ and $w_{i k}$ in global and partial value functions [30] 
The model calculates $a_{i}-1$ variables $w$ for each criterion $i$, and $a-1$ variables $z$ for the global satisfaction. If $a_{i}$ is the same for all $i$, the model requires at least $\left(a_{i}-1\right)$ $n+a-1$ customer evaluations.

By solving the previous problem, the initial variables can be calculated as:

$$
\begin{aligned}
& b_{i}=\frac{1}{100} \sum_{t=1}^{a_{i-1}} w_{i t} \text { for } i=1,2, \ldots, n \\
& y^{* m}=\sum_{t=1}^{m-1} z_{t} \text { for } m=2,3, \ldots, a \\
& x i^{* k}=100 \frac{\sum_{t=1}^{k-1} w_{i t}}{\sum_{t=1}^{k-1} w_{i t}} \text { for } i=1,2, \ldots, n \text { and } k=2,3, . ., a_{i}
\end{aligned}
$$
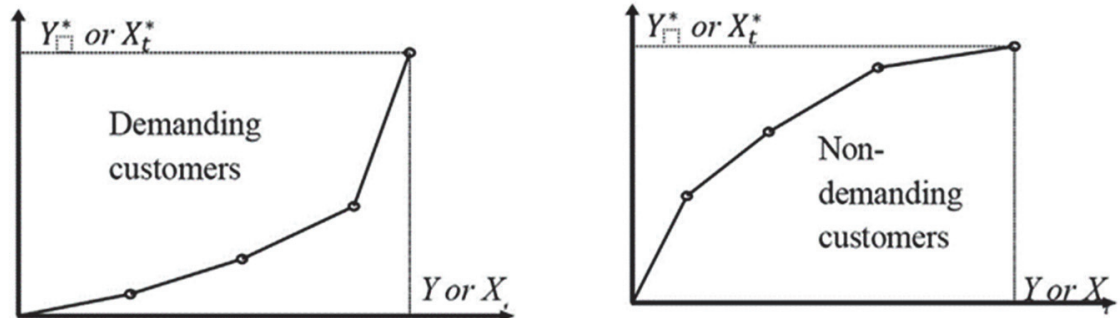

Figure 4 Customer satisfaction curves with different demanding levels [30]

The main results of the VAZP model are reflected through the value of passenger satisfaction as well as obtaining the relative importance (weights) for each criterion and sub-criterion.

They range from $[0,100]$ to the actual value assigned to the passenger by each level of the total $Y$ or marginal $X_{t}$ scale of ordinal satisfaction. The shape of the curve of these functions shows the degree of requirement for the evaluation of the transport service by the passenger's (Fig. 4).

For Neutral customers, the linear value function is flat, the more satisfied the customers are, the linear value function is more straightforward. In the case of Demanding customers that are not actually satisfied with the quality of the transport service, the linear value function takes on a convex shape. The linear value function, which shows a concave shape, indicates Non-demanding customers who express a high level of satisfaction with quality transport service even when their expectations are not met in one segment. The weight values of the satisfaction criteria show the importance of the offered elements of quality transport service. In order to determine the value of linear functions, it is important to determine the ratio of the weight of the criteria and the importance of the elements of quality transport service.

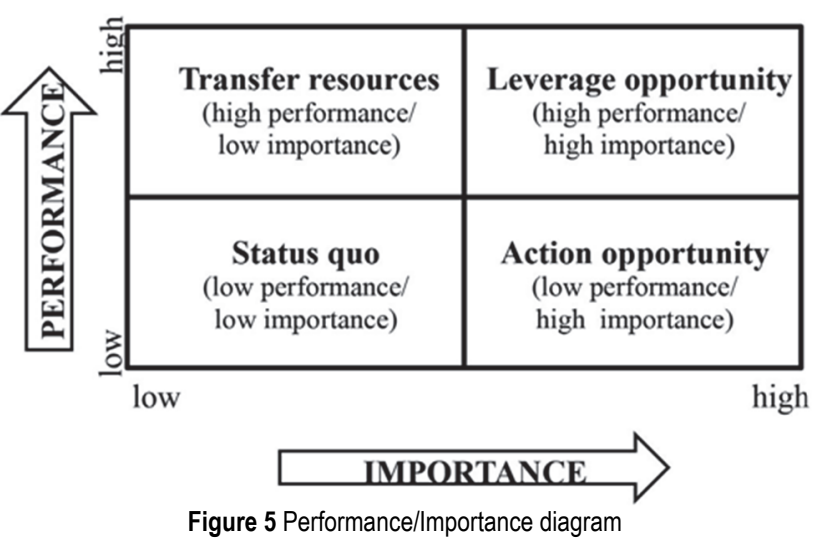

The relationship between the importance of the weight of the criteria and the satisfaction index results in a
Performance/Importance development diagram. The lower right quadrant represents the most important part of the diagram that has the first priority in business decision making. The upper right quadrant is a second priority especially if there is room for improvement in making business decisions to improve the quality of transport service. The third priority is the lower left quadrant which is relatively important for the company.

Finally, the last priority of the company is the upper left quadrant which the quality of transport service should be improved while the success of the company's business decision is relatively good (Fig. 5).

In order to obtain the weight values of the criteria and sub-criteria, it is necessary to determine their consistency and the ratio between the criteria of the transport service and the alternatives (Bus companies). Thus, established and evaluated criteria and sub-criteria make the VAZP model effective for evaluating the quality of transport services by applying the analytical-hierarchical procedure (Fig. 6).

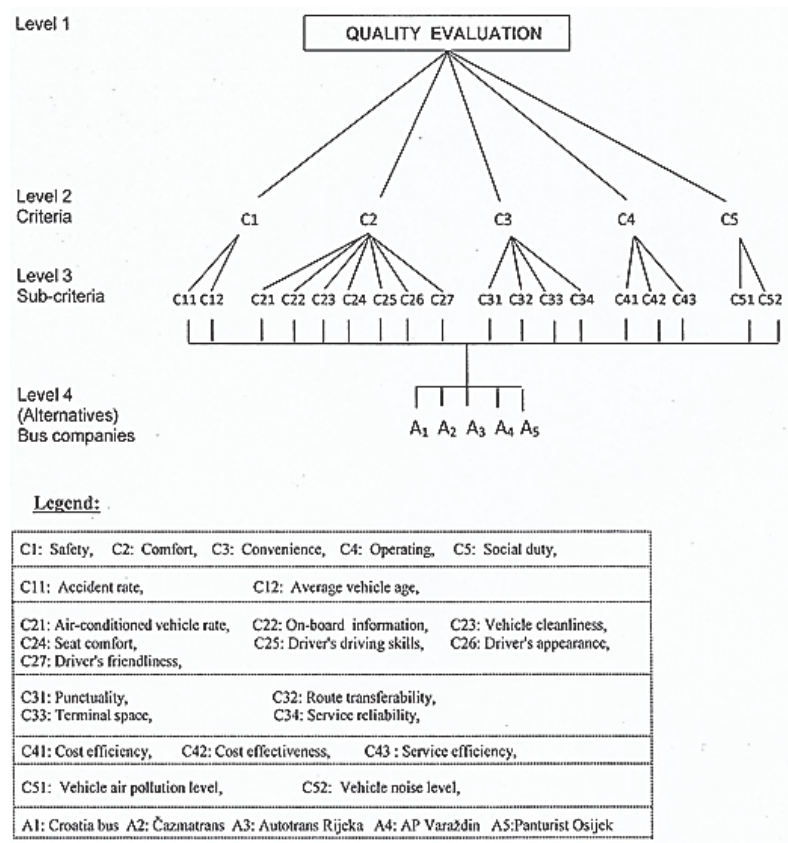

Figure 6 Hierarchical structure for quality service evaluation in bus companies 


\section{THE CASE OF CROATIA BUS COMPANIES}

Today in the Republic of Croatia intercity bus transport is well developed and at the same time the network of bus lines that connects almost entire country is very well developed. The bus network covers cities and larger settlements, while the problem arises in less populated areas where there are no buses or there is a line that runs once or several times a day. According to the Statistical Office of the Republic of Croatia, in the period from 2013 to 2019, bus traffic increased by 22 million kilometers, which is related to the increase in the number of buses in general [31].

In a period of five years, the number of buses increased by 476 buses and more than 21000 seats, which indicates a growing trend in demand for this form of transport. Due to growing demand, bus carriers have significantly increased their fleet. The average number of seats in 2018 (46.1 seats) did not exceed the figure from 2013 (46.3 seats), which means that the number of buses is growing slightly faster than the number of available seats. As expected, with the increase in the number of buses, the number of standing and sitting passenger seats also increased by 26741 seats.

It can be seen that the number of kilometers traveled by buses in the observed period increased by $20.7 \%$, while the kilometers traveled by buses with passengers increased by $24.56 \%$. In the total number of passengers transported by buses, most passengers traveled within the limits of domestic transport. Also, at the same time, the number of transported passengers decreased by 4.7 million passengers. This trend indicates the extension of bus lines, that the existing ones show reduced occupancy, but also a smaller number of bus users.

In recent years, a number of new transport companies have been established. In order to exist bus companies must be able to monitor the competition imposed on them, they need to optimize their business and improve the quality of transport service on intercity lines. The goal of the optimization of road transport of passengers in intercity transport is: improve the essential elements of the quality of transport services resulting in a higher level of its overall quality, reduce operating costs and the possibility of gaining a competitive advantage over other carriers.

For the purposes of this research, the evaluation of the quality of transport service on the intercity passenger line Zagreb (Croatia) to Stuttgart (Germany) will be carried out. The subject line on which the research will be conducted was chosen because it is operated by a large number of road carriers and has a high frequency of departures and as such it is representative for evaluating the quality of transport services. The research includes an analytical assessment of the objectives of the passenger satisfaction survey which also includes an analysis of the behavior and market environment of the passengers. Thus, a general attitude of the user about the transport service provided by the business organization (Bus company) can be obtained.

Passenger satisfaction with the quality of transport service of five different bus carriers was examined on the intercity passenger line in question. The questionnaire was distributed to passengers immediately before using the transport service. Passengers filled in the questionnaire manually during the trip, and after the trip was completed, they handed over the questionnaire to the driving staff. Thus, the collected data were used for further processing and multi-criteria analysis using a new model for assessing the quality of transport services based on the measurement of passenger satisfaction. A survey of the quality of transport service of various bus carriers on the mentioned intercity passenger line was conducted on March 4, 2020.

\section{RESULTS OF VAZP METHODOLOGICAL APPROACH}

If we take the curve and the index of total passenger satisfaction (Fig. 7), analysis of the data and the obtained research results showed that passengers are very satisfied with the provided transport service because the measured value of the average global satisfaction index is $84 \%$. As the value-added curve for the passenger group has a concave shape, the analysis of the results showed that the majority of the total passenger group consists of undemanding passengers. Further analysis of the collected data showed that passengers are very satisfied with all criteria, except the Social duty criterion (Fig. 8). The criterion that the passengers rated with the highest points and with which they are the most satisfied is Comfort criterion.

According to the relative importance of the weights of the criteria (Fig. 9), one of the criteria that passengers rated as the most important criterion in the conducted research is the Comfort criterion. Namely, it shows that passengers want to ride in comfortable buses and that this criterion includes as many possible assessment items (sub-criteria). The rest of the criteria that were evaluated have approximately the same importance of weight, except for the Social duty criterion. Obviously, those passengers who consider the Social duty criterion very important prefer to travel with buses that have a lower air pollution emissions and that make less noise.

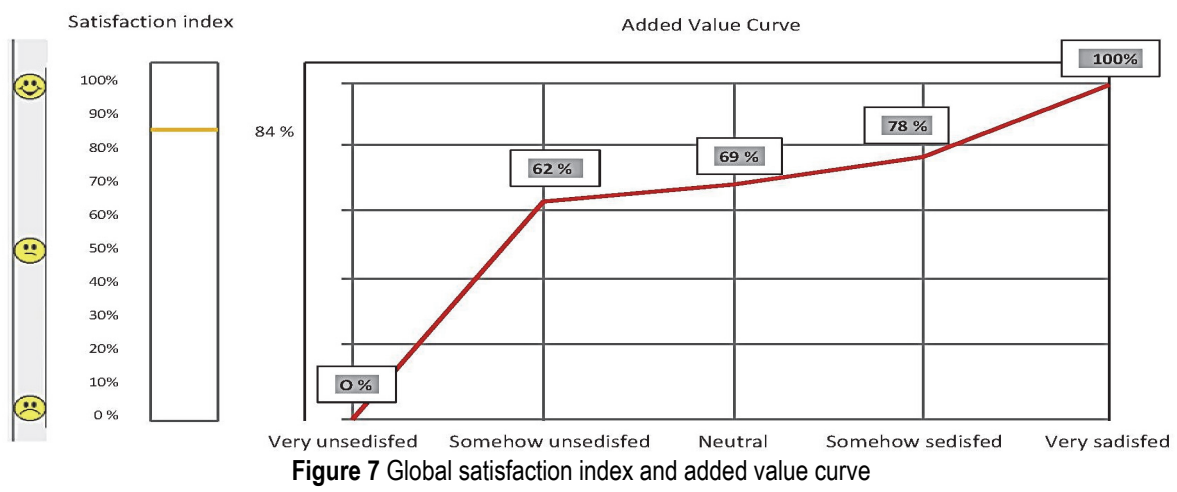




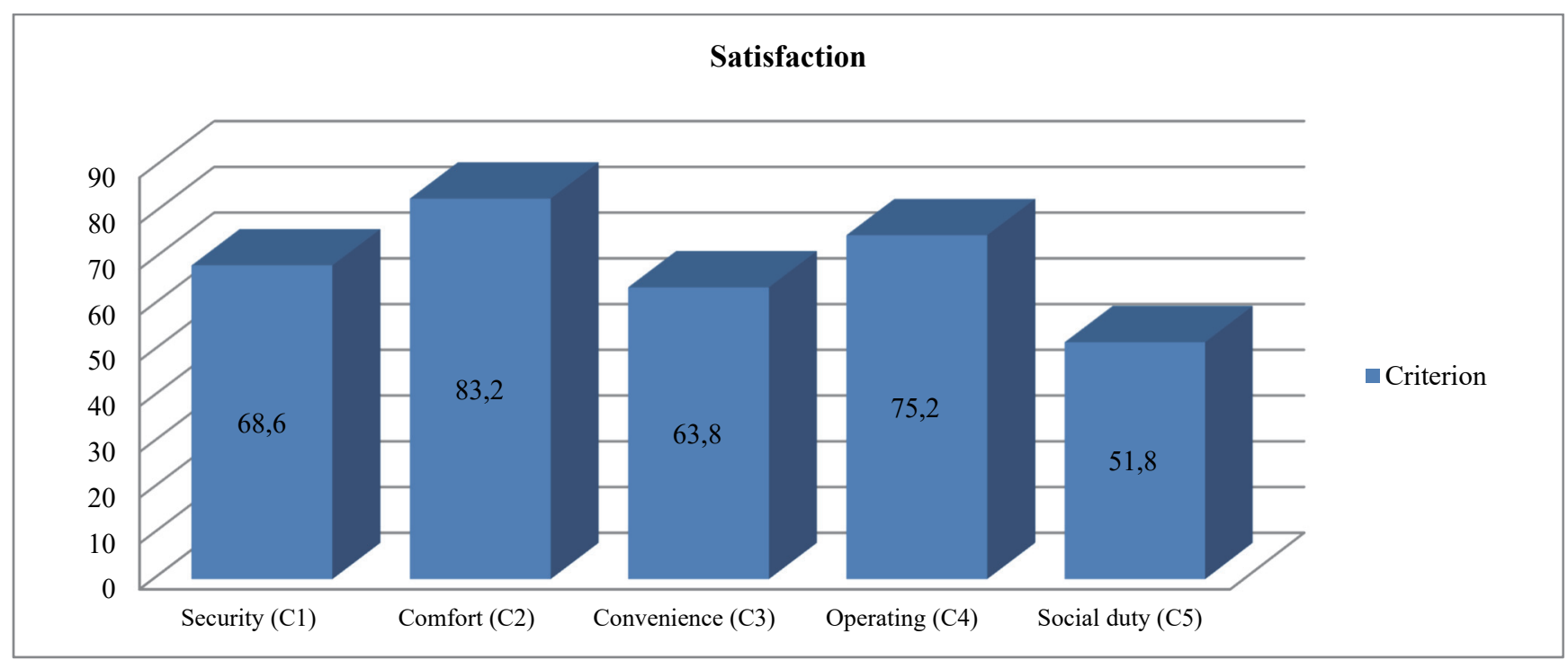

Figure 8 Satisfaction levels for each criterion

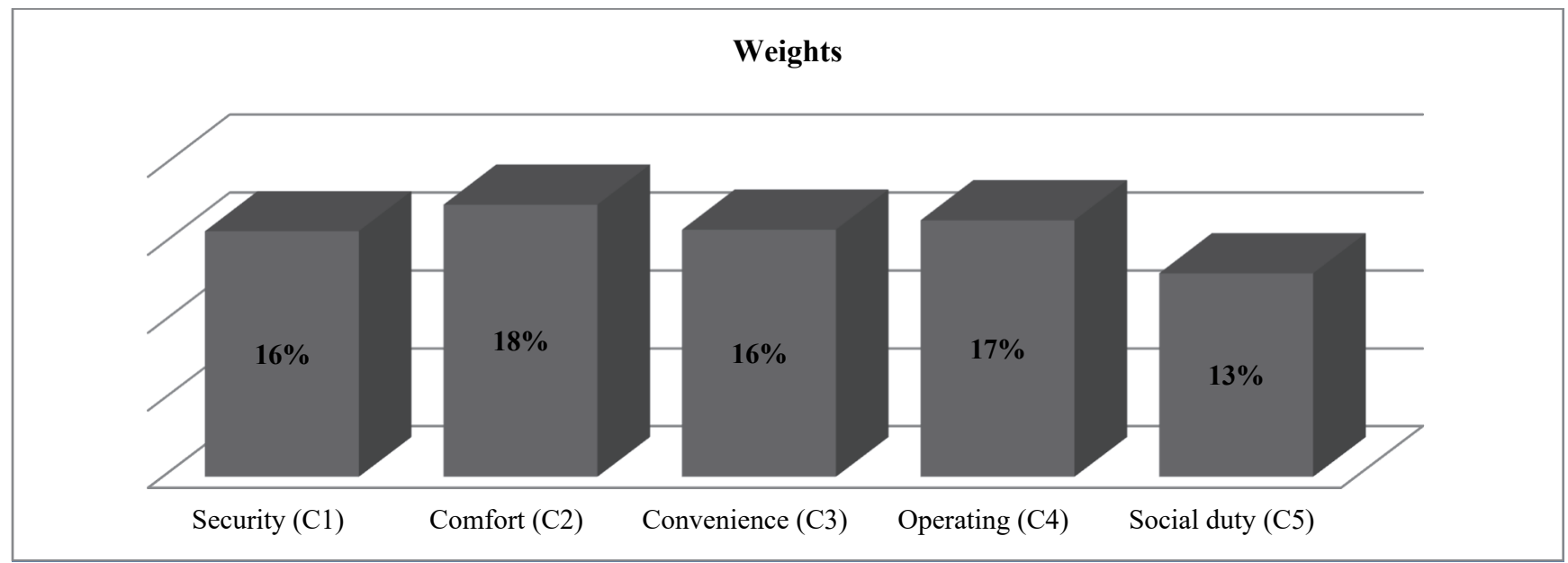

Figure 9 Importance level for each criterion (weights)

\subsection{Partial and Segmentation Satisfaction Analysis}

The results of the research can be presented through partial and segmentation analysis, which is important in order to identify individual groups of passengers since the methodology is based on a collective model.

Fig. 10 shows the hierarchical structure of all criteria and sub-criteria with a certain level of passenger satisfaction as well as with the corresponding weight values. The analysis of the data revealed the following:

Security $(C 1)$ - passengers are relatively satisfied with the security aspect of the transportation. They are somewhat more satisfied with the sub-criterion of the accident rate $(76 \%)$, while they are less satisfied with the sub-criterion average vehicle age (57\%).

Comfort (C2) - passengers rated the cleanliness of the vehicle and seat comfort as the most important sub-criteria, while they were the least satisfied with the air conditioning of the vehicle and the appearance of the drivers, which they rated as modest $(26 \%)$.

Convenience (C3) - the criterion Convenience mainly refers to the punctuality of the buses lines, the possibility of transfer, terminal space and the reliability of the service with which passengers are most satisfied (87\%).

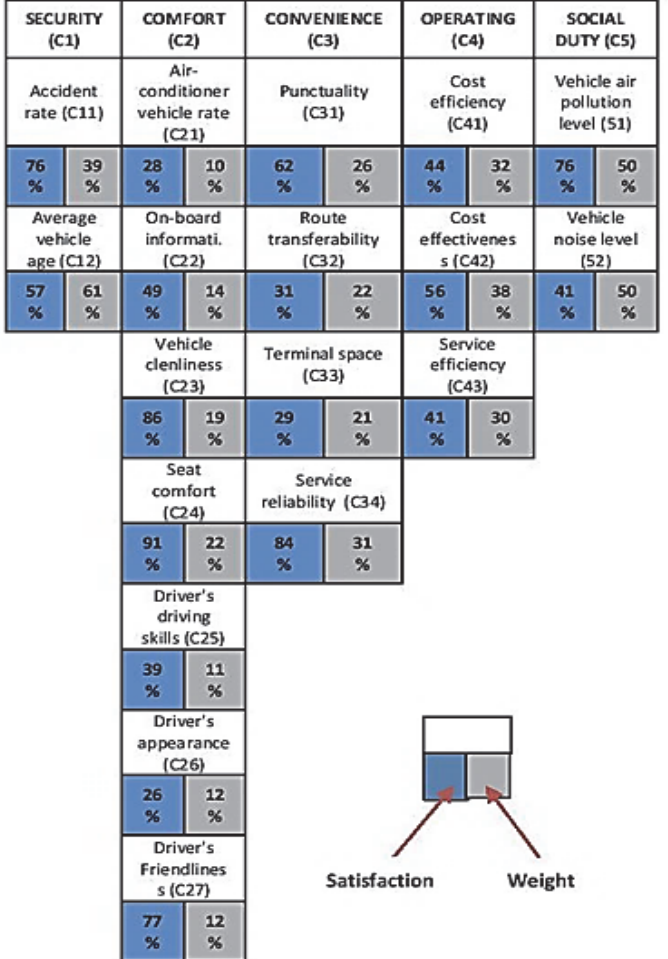

Figure 10 Hierarchical structure and analytical results of customer's satisfaction dimensions 
Operating (C4) - these three sub-criteria can be used to represent the input of services, service results and consumption of public transport and operating of the bus company. All three indicators are roughly equally rated by passengers.

Social duty $(C 5)$ - passengers are relatively satisfied with the environmental aspect where they are somewhat more satisfied with the vehicle air pollution sub-criterion $(76 \%)$, while they are less satisfied with the vehicle noise generation $(41 \%)$.

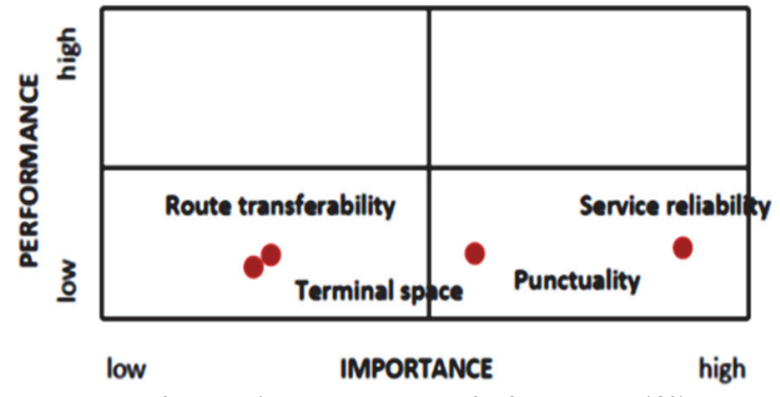

Figure 11 Performance/Importance diagram for Convenience (C3) criterion

Following the above data analysis, it is possible to define a diagram. The Performance/Importance diagram presents the deficient and potentially critical elements of transport service quality. The presented graph shows the current state of passenger satisfaction in relation to the previous results obtained in the research. The analysis of the overall set of criteria shows that passengers are poorly satisfied with the Convenience criterion, although this criterion is less important to them, it could be potentially poor indicator for business policy of the company for road passenger transport (Fig. 11).

\subsection{Analysis of Data in the Expert Choice Program}

An effective tool for resolving multicriteria decisionmaking is Expert Choice. It is a robust application designed for a computer (PC), which enables teams to prioritize sorting alternatives, and make reliable decisions about alternatives to achieve the desired goals. It is useful for scenarios in strategic budget planning and traffic projects. Expert Choice is fully applicable to the AHP method and supports all necessary steps [32]. It enables multiple way problem structuring and comparison of alternatives and criteria in pairs in multiple ways, and also provides the ability to conduct and visualize sensitivity analysis based on a simple interactive method of weighting criteria and analysis.

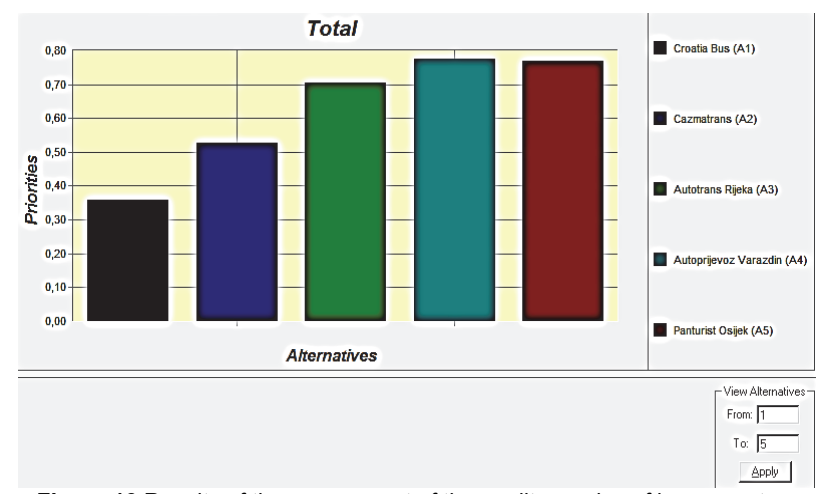

Figure 12 Results of the assessment of the quality service of bus operators
Fig. 12 shows the overall assessment of the performance of all carriers according to the results of the survey and the subjective assessments of the surveyed passengers. It was determined that the company Croatia Bus has, on average, the worst quality of transport service on the observed line in relation to other transport companies covered by the survey. The research also established that the company Panturist Osijek on the subject line provides the best quality of transport service in the overall satisfaction of passengers.

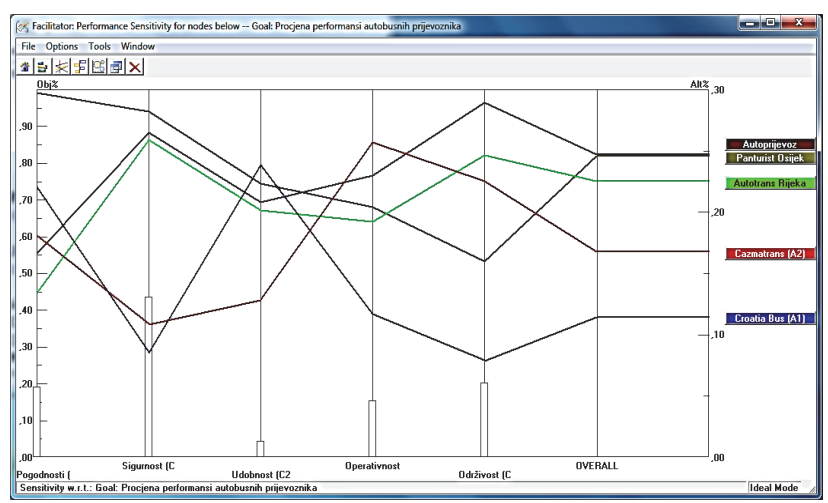

Figure 13 Sensitivity analysis of the quality service of bus operators

Fig. 13 shows the so-called Performance graphical representation of the impact of individual criteria on alternatives (bus carriers). It reflects the effects of particular criteria weights on the current and overall ranking of alternatives. The current ranking of alternatives represents the change in priority of an alternative influenced by the weight of one criterion, and the overall ranking of alternatives represents the ranking of alternatives influenced by the weight of all criteria. The diagram shows that the Croatia Bus alternative is positively affected by the comfort criterion, while the security and sustainability criteria negatively affect the alternative.

\section{CONCLUSION}

Multi-criteria decision making in practice is an extremely complex process with a variety of applications in all areas of human activity. In the presented considerations, the aim was to demonstrate the application of multi-criteria analysis in problem solving, with a focus on solving various types of problems, especially in the domain of passenger transportation. This paper shows how the VAZP methodological approach can be used to measure passenger satisfaction and how certain elements of transport service quality need to be improved and enhanced. Applying this methodology on passenger satisfaction in bus transportation, the overall and individual level of satisfaction can be assessed, which may indicate the shortcomings and advantages of individual companies for road passenger transport compared to others. Future changes in the passenger bus market may affect the wishes and expectations of passengers. For example, some dimensions of satisfaction may become critical in the near future if passengers give more importance to them.

Using quality computer programs, evaluation of service quality can be determined relatively quickly with a high degree of reliability, but nevertheless it is necessary to carry out a detailed analysis in order to understand the 
impact of each criterion or condition considered in its adoption. The evaluation process and the corresponding outcomes using this methodology can help passenger transport companies to recognize their advantages over competitors in a particular management and decision making context Also, this approach opens up further research on this issue and possible further extension of the number of organizational factors that are of importance to quality. Once the necessary organizational preconditions have been realized, it is possible to realize the transport service through the applying of principle of business excellence.

\section{REFERENCES}

[1] Buble, M. (1997). Strategic Management. Scientific book Faculty of Economics, University in Split, Croatia.

[2] Lazibat T., (2009).Quality Management, Scientific book, University in Zagreb, Croatia.

[3] Županović, I. (1986). Road Traffic Technology. Scientific book, Faculty of Transportation and Traffic Sciences, University in Zagreb, Croatia.

[4] Rajsman, M. (2017). Technology of Passengers Transportation in Road Traffic. Scientific book, Faculty of Transportation and Traffic Sciences, University in Zagreb, Croatia.

[5] Bubalo, T., Vojvodić, H. \& Bokulić, D. (2015). The exchange of data in the intercity bus traffic. $23 \mathrm{rd}$ Telecommunications Forum, TELFOR. https://doi.org/10.1109/TELFOR.2015.7377387

[6] Bubalo, T., Jurčević, M., \& Steiner S. (2017). Analysis and Strategic Planning of Bus Passenger Transport with Reference to the Status of Croatia 25th International Symposium on Electronics in Transport ISEP.

[7] International Association of Public Transport UITP Retrieved from http://www.uitp.org/

[8] Jurčević, M., Bubalo, T., \& Mandžuka, B., (2018). Influence of Costs on the Optimization of Transport Routes (case study). Journal Econviews, University in Osijek, 1, 65-73.

[9] Poku-Boansi M., Adarkwa K.K., (2013). The determinants of demand for public transport services in Kumasi Ghana. Journal of Science and Technology, 33(3), 60-72. https://dx.doi.org/10.4314/just.v33i3.7

[10] Sam, E. F., Hamidu, O. \& Daniels, S., (2018). SERVQUAL analysis of public bus transport services in Kumasi metropolis Ghana: Core user perspectives. Case Studies on Transport Policy, 6(1), 25-31. https://doi.org/10.1016/j.cstp.2017.12.004

[11] Kumar, H., Nomesh, S., \& Tiwarib, B. (2018). Perception of potential bus users an impact of feasibile interventions to improve quality of bus services in Delhi. Case Studies on Transport Policy, 6(4), 591-602. https://doi.org/10.1016/j.cstp.2018.07.009

[12] Le-Klähn, D. T., Hall, C. M., \& Gerike, R. (2014). Analysis of visitor satisfaction with public Transport in Munich. Journal of Public Transportation, 17(3), 68-85. https://doi.org/10.5038/2375-0901.17.3.5

[13] Burgdorfb, C., Eisenkopf, A., \& Knorrc, A. (2018). User acceptance of long distance bus services in Germany. Research in Transportation Economics, 69, 270-283. https://doi.org/10.1016/j.retrec.2018.07.023

[14] Eboli L., Mazzulla G., (2007). Service quality attributes affecting customer satisfaction for bus transit. Journal of Public Transportation, 3, 3-10. https://doi.org./10.5038/2375-0901.10.3.2

[15] Eboli, L. \& Mazzulla, G. (2008). A stated preference experiment for measuring service quality in public transport. Transportation Planning and Technology, 31(5), 509-523. https://doi.org/10.1080/03081060802364471
[16] Nutsugbodo, R. Y. (2013). Tourist's perceptions of the quality of public transportation services in the Accra metropolis: a Servqual approach. African Journal of Hospitality, Tourism and Leisure, 2(4), 1-8.

[17] Barbino, B., Deiana, E. \& Tilocca P. (2012). Measuring service quality in urban bus transport: a modified servqual approach, International Journal of Quality and Service Sciences, 4(3), 238-252. https://doi.org/10.1108/17566691211269567

[18] James, J., Lioua, H., Yun, C.H., \& Chenb, S. (2014). Improving transportation service quality based on information fusion. Transportation Research: Policy and Practice, 67, 225-239. https://doi.org/10.1016/j.tre.2015.05.010

[19] Guner, S. (2018). Measuring the quality of public transportation systems and ranking the bus transit routes using multi-criteria decision making techniques. Case Studies on Transport Policy, 6(2), 214-224. https://doi.org/10.1016/j.cstp.2018.05.005

[20] Nassereddine, M. \& Eskandari, H. (2017). An integrated MCDM approach to evaluate public transportation systems in Tehran. Transportation Research Part A: Policy and Practice, 106, 427-439. https://doi.org/10.1016/j.tra.2017.10.013

[21] Maha, A., Bobalca, C., \& Tugulea, O. (2014). Strategies for the Improvements in the Quality and Efficiency of Public Transportation. Procedia Economics and Finance, 15, 877885. https://doi.org/10.1016/S2212-5671(14)00551-6

[22] Ona, J., Ona, R., Eboli, L., \& Mazzulla, G. (2013). Perceived service quality in bus transit service: a structural equation approach. Transport Policy, 29, 219-226. https://doi.org/10.1016/j.tranpol.2013.07.001

[23] Hensher, D., Stopher, P., \& Bullock P. (2001). Developing a service quality index (SQI) in the provision of commercial bus contracts. Journal of public transportation, 3, 52-65.

[24] Hensher, D., Mulley, C., \& Yahya, N. (2010). Passenger experience with quality bus service: the tyne and wear "superoute" services. Transportation, 37(2), 239-256. https://doi.org/10.1007/s11116-009-9240-x

[25] Garrido, C., Ona, R., \& Ona, J. (2014). Neural networks for analyzing service quality in public transportation. Expert Systems with Applications, 41(5), 6830-6838. https://doi.org/10.1016/j.eswa.2014.04.045

[26] Berežny, R. \& Konečny, V. (2019). The quality standardization in suburban bus transport by the transformation of the service quality loop. Transportation Research Procedia, 40(1), 955-962. https://doi.org/10.1016/j.trpro.2019.07.134

[27] Drljača, M. \& Sesar V. (2019). Quality factors of transport process. Transportation Research Procedia, 40(2), 10301036. https://doi.org/10.1016/j.trpro.2019.07.144

[28] Marimon, F., Llach, J., Alonso-Almedia, M., \& MasMachuca, M. (2019). CC-Qual: A holistic scale to assess customer perceptions of service quality of collaborative consumption services. International Journal of Information Management, 49(1), 130-141. https://doi.org/10.1016/j.ijinfomgt.2019.03.009

[29] Grigoroudis, E. \& Siskos Y. (2002). Prefference disaggregation for measuring and analysing customer satisfaction: The Musa method. European Journal of Operational Research, 143(1), 148-170. https://doi.org/10.1016/S0377-2217(01)00332-0

[30] Grigoroudis E., Siskos Y., (2010). Customer satisfaction evaluation methods for measuring and implementing service quality. Operations Research \& Management Science. https://doi.org/10.1007/978-1-4419-1640-2

[31] Statistical Reports. 2018. Transport and Communication/ Statistical Yearbook for the period 2009-2017. Croatian Bureau of Statistics. Zagreb, 2019.

[32] Aleksi, I. \& Hocenski Z. (2009). Application of Expert Choice Tool and AHP-Elaborate. Faculty of Electrical Engineering, University in Osijek, Croatia 


\section{Contact information:}

Tomislav BUBALO, mag. ing. traff., PhD student

(Corresponding author)

University of Zagreb,

Faculty of Transportation and Traffic Sciences,

Vukelićeva 4,10 000 Zagreb,Croatia

E-mail: tomislav.bubalo@gmail.com

Marijan RAJSMAN, PhD, Full Prof.

University of Zagreb,

Faculty of Transportation and Traffic Sciences,

Department of Road transport,

ZUK Borongaj, Borongajska cesta 83a,10 000 Zagreb

E-mail: marijan.rajsman@fpz.hr

Pero ŠKORPUT, PhD, Assis. Prof.

University of Zagreb,

Faculty of Transportation and Traffic Sciences,

Department of Intelligent Transportation Systems,

ZUK Borongaj, Borongajska cesta 83a,10 000 Zagreb

E-mail: pero.skorput@fpz.hr 